\title{
Pathologic Stage IIB Esophageal Squamous Cell Carcinoma AJCC v8
}

National Cancer Institute

\section{Source}

National Cancer Institute. Pathologic Stage IIB Esophageal Squamous Cell Carcinoma

A/CC v8. NCl Thesaurus. Code C133535.

Stage IIB includes: (T3, N0, M0, G2-3, Tumor location: Upper/middle); (T3, N0, MO, GX, Tumor location: Any); (T3, N0, M0, Any G, Tumor location: Unknown); (T1, N1, M0, Any G, Tumor location: Any). T1: Tumor invades the lamina propria, muscularis mucosae, or submucosa. T3: T umor invades adventitia. N0: No regional lymph node metastasis. N1: Tumor with metastasis in one or two regional lymph nodes. M0: No distant metastasis. GX: Grade cannot be assessed. G2: Moderately differentiated. G3: Poorly differentiated, undifferentiated (AJCC 8th ed.) 